\title{
The Impact of Digital Transformation on Banking
}

\author{
Hanen Khanchel ${ }^{1}$ \\ ${ }^{1}$ Institute of Advanced Business Studies, Carthage, Tunisia \\ Correspondence: Hanen Khanchel, Institute of Advanced Business Studies, Carthage, Tunisia.
}

Received: October 4, 2019

Accepted: October 14, 2019

Online Published: November 4, 2019

doi:10.5430/jbar.v8n2p20

URL: https://doi.org/10.5430/jbar.v8n2p20

\begin{abstract}
In this paper, we discuss in more detail the context of Tunisian banks, with a focus on digital transformation strategies considered, the mission that preceded this study and the methodology and approach. Secondly, we will analyze the results of the study to reconstruct the features of the digital transformation of movement in Tunisian banks.

The study of the digital transformation of Tunisian banks is carried on the board Matine Consulting firm. This study is launched in the continuity of the inaugural training program certifying on the topic of FinTechs and digital transformation of banks, set up by Matine in collaboration with the Academy of Banking and Finance (ABF).
\end{abstract}

Keywords: digital transformation, strategies, fintech, Bank, Tunisia

\section{Introduction}

The speed with which the world is evolving so quickly that it has radically changed our behavior and uses. In the last decade, the development of digital has impacted all possible fields of activity, and is immersed in our daily lives to become the currency. Today, global penetration rates on the Internet and the number of connected devices reach the record. In 2019, 57\% of the world population have access to the Internet, with 26 billion devices connected according to figures from Statista. These connected objects daily generate millions of gigabytes, according to Forbes, and, over the past two years, $90 \%$ of the data in the world were generated from the same source (Sharf, 2015).

The digital revolution has not spared the world of finance (Vauplane, 2019). The development of digital technology and the emergence of new technologies, including Big Data or Blockchain, opened the door to innovations in the mode of delivery of financial services. These innovations have been boosted by a consumer "digital ready" hyper-taker and digital solutions. All innovations and mutations that affected the usual profile of consumers have given rise to new players on the market, namely FinTechs (Floer, 2018). These actors have struggled much during their early years, have recently begun to establish itself among the great, and to announce as real alternatives to existing solutions.

Banks, for their part, have been heavily impacted by the changes that affected their environment, namely the emergence of FinTech and the changing customer profile (Fox \& Greenspan, 2019). This changing environment prompted them to start thinking about the redefinition of their services and the banking model (Scholten, 2019). That's when the digital transformation initiatives have emerged in order to align banks with new trends in the use of digital technology and technology adoption. What then is the impact of digitization on financial services?

This paper aims at defining digital transformation in the Tunisian banking sector, outlining what banks and FinTech are both developing in the Tunisian market, and also pointing out that it is not going to be the technology itself that will be the disruptor of the banking sector, but rather how company deploys the technology that will cause the disruption?

In what follows, we will try to answer theses questions. First, by examining the various impacts of digitization on the environment of banks. Then we will evaluate the consequences of these mutations on the banks themselves, both in the digital transformation of the relationship with FinTechs. Finally, we will conduct a survey of Tunisian banks to identify trends prevailing on their digital transformations.

\section{Background}

In Tunisia, the penetration rate of more and more important in smartphones and the launch of $3 \mathrm{G}$, followed by $4 \mathrm{G}$ that Internet penetration reaches high levels. Indeed, according to the Global Digital postponement of We Are Social, 
the Internet penetration rate in Tunisia was $68 \%$ in 2018, a rate close to the European average is $80 \%$ for the same year. This makes a total of 7.89 million active Tunisian Internet. This figure is revised upwards for the year 2019. As for social networks, their penetration rate reached in turn $62 \%$ in January 2018. This reflects a highly interconnected community.

All these statistics show that the Tunisian consumer is beginning to achieve some digital maturity, and the use of digital technology has become part of everyday life. However, supply is still not living up to those expectations, or it has not succeeded yet convincing, especially in financial services. The statistics provided by the World Bank are the perfect witness :

Table 1 . Use of digital consumer by the Tunisian

\begin{tabular}{ll}
\hline$\%$ Of adults having paid bills online & $3.4 \%$ \\
\hline$\%$ Of adults having made payments online & $6.8 \%$ \\
\hline$\%$ Of unbanked adults who accessed their accounts via the web/mobile & $10 \%$ \\
\hline$\%$ Of unbanked adults who have shopped online & $4.6 \%$
\end{tabular}

Source: World Bank, 2016.

Digitalization offers new opportunities for banks to place the customer at the center of the development process. New technologies seem to be and stay in the market to disrupt the retail financial service value chain, as well as introducing Fintech into the competitive arena. Incumbents and new comers have innovative levers to adopt. The forces shaping these changes have led the sector to take part of the role of banking and finance, a provider of financial services.

It is in this context that we decided to conduct a survey of Tunisian banks to assess their digital offering and identify different strategies as to their possible transformations thus establish a synthesis of the state of advancement of digital technology in our Tunisian banks.

\subsection{Presentation of the Cabinet: Matine Consulting}

Based in Tunis, Matine has two offices in Paris and Dubai. It operates on behalf of large companies, major banks, governments, international organizations and NGOs on high-level decisions. With a team of qualified and versatile consultants and a network of international experts, Matine Consulting is involved in various types of missions, including the definition of strategic, commercial and operational efficiency, deployment and change management, the consolidation process, the digital processing...

Matine Consulting incorporates within its structure a unit specializing in banking and financial services. This unit has accompanied financial institutions internationally (Europe, Africa and Middle East) on projects related to the definition of their operating models, the migration of their information systems, reengineering their back offices, the dematerialisation of their process ...

During my internship, I joined the bank unit and financial services. The mission on which I worked was the FinTech Academy: A training course set up by certifying Matine Consulting in collaboration with ABF.

\subsection{Training Cycle: FinTech Academy}

In 2018, the Academy of Banking and Finance (ABF), banking and financial training structure from the Tunisian Professional Association of Banks and Financial Institutions (APTBEF), appealed to Matine Consulting to implement a cycle certifying training around FinTechs and new areas of innovation that result.

The training course is intended for executives of banks and leasing in Tunisia. It aims to provide a comprehensive view on the landscape of FinTechs and new revenue models around financial services and major technological innovations and their main use cases (Lieber, 2014). As a result, allow the participant to lead a reflection on the future of the provision of financial services, and prepare for possible digital transformations in her body.

Matine Consulting has supported the design cycle, with the objective of enhancing the content in order to reach the various subjects of interest to banks in their digital transformation. This resulted in a session spanning four months of study (March 2019 - June 2019) and has 12 training days, each dedicated to a specific module. At the end of the 
session, a final evaluation is planned, after which Matine and ABF will issue certificates to participants who successfully completed the training cycle. The following is the list of 12 cycle modules:

Table 2. The Academy training modules FinTech

\begin{tabular}{ll}
\hline 1 & Panorama digital trends, actors and regulations \\
2 & banking distribution models \\
3 & digital processing \\
4 & Open Banking \\
5 & Blockchain \\
6 & Digital Payments \\
7 & Data Analytics \& Artificial Intelligence \\
8 & Digital marketing \\
9 & alternative financing \\
10 & Regtechs, Compliance \& Risk Management \\
11 & algorithmic trading \\
12 & Crypto Economy \\
\hline
\end{tabular}

Source: Matine Consulting, 2018.

To ensure all training, Matine Consulting has appealed to international experts in each field, who shared their expertise with practical cases and experience feedback.

During my internship, I was entrusted with the preparation of course materials in the first two modules: "Panorama digital trends, actors and regulation" and "banking distribution models." Namely, two documents of about 70 to 80 slides each. These documents provided the media during training days, and were distributed to participants to use it to prepare for the final exam to be held at the end of the cycle.

I was also required to help trainers modules "digital marketing", "alternative financing", "algorithmic trading" and "Regtechs, Compliance \& Risk Management" in the preparation of their courses by providing ready to integrate into slides their media, but also the layout of their documents under Matine format. My mission was also to develop interactive exercises during training days (Quiz, surveys, case studies, brainstorming ...). All on a digital tool "Klaxoon" that allows participants to interact with the speaker, publish post-it or answer quizzes and surveys via his mobile phone.

The preparation of course materials, with all the documentation needed to do, and my presence at training days, allowed me to develop an idea on the subject of digital, and have been to me an unmatched support for the drafting of two chapters above.

This is a continuation of the cycle of training that we decided in Matine Consulting to launch a study on the digital transformation of Tunisian banks, especially the digitalization of movements within these institutions are beginning to be felt.

\section{Methodology}

The study of digital transformation has taken the form of a survey to distribute to Tunisian banks. This survey includes fifteen multiple choice questions, covering the 3 following themes:

- Approach to digital conversion,

- Areas of investment,

- Relationship with FinTech.

All these themes define the digital transformation strategy adopted by the bank, but also its status and its relationship with its environment, including new actors instead. 
First, the questionnaire was prepared by trying to expand the content of the questions as well as possible responses to ensure good coverage of various topics of digital transformation. The questionnaire was implemented on Google Forms. A document accompanying PowerPoint has also been set up in order to explain to answering the context of the study, its objectives, the topics addressed and the practical arrangements that follow (addresses to contact in case of need, the results return conditions, study schedule ...). Second, and to ensure the receipt of the inquiry, Matine appealed to $\mathrm{ABF}$, who is responsible in turn to distribute the survey to the 25 member banks of the Tunisian Professional Association Banking and Financial Institutions (APTBEF). An email containing the questionnaire and the accompanying document has been sent to branches of banks and training managers. They were in charge of directing it to the person authorized to answer, namely bringing the topic of digital transformation in the institution.

\section{Results}

After sending the questionnaire by email, we received 10 responses from Tunisian banks following:

Table 3. Stock responding to the digital processing

\begin{tabular}{llll}
\hline 1 & Arab International Bank of Tunisia (BIAT) & 6 & Banque Nationale Agricole (BNA) \\
\hline 2 & Attijari Bank of Tunisia (Attijari Bank) & 7 & Amen Bank \\
\hline 3 & Banque de Tunisie (BT) & 8 & Zitouna Bank \\
\hline 4 & Société Tunisienne de Banque (STB) & 9 & Baque Tuniso-Koweitienne (BTK) \\
\hline 5 & Housing Bank (BH) & 10 & Wifak International Bank \\
\hline
\end{tabular}

Source: Matine Consulting, 2018 Source: Matine Consulting, 2018.

In the following we will analyze the survey results, grouped by thematic issues.

\subsection{Digital Processing Approach}

The digital transformation approach differs from one bank to another. It defines the first base of the transformation, namely the way in which the bank approaches its digitization project, on which axes does so act as a priority, which organization to implement and what are the main challenges. Half of the banks surveyed said they have a comprehensive strategy for digital transformation. This shows that banks have realized the digital challenge, and began to respond, including through the establishment of strategic plans for digital transformation. Indeed, a comprehensive transformation strategy can be very beneficial for the bank in question, as this involves establishing a prior diagnosis of the existing, notably in key transformation projects, namely digital culture banking, technology and deployment architectures, control data, customer knowledge ... Secondly, the formalization of the vision and strategic objectives by identifying digital transformation projects and their prioritization. Finally, developing a plan of action while defining the dedicated budget. A global transformation strategy often ends by driving the change that accompanies employees through an internal communication plan and training sessions

On the other side, $40 \%$ of banks say they have conducted isolated initiatives digitizing without having a comprehensive plan. These initiatives include the acquisition of digital solutions to integrate into the core banking, automation of some processes. In conclusion, almost all Tunisian banks (90\% of the banks surveyed) engage in the digital transformation projects, aiming to ally the new needs of consumers, but for agility and reduce costs. To do so, each bank setting of priorities to lead its digital transformation.

Most banks in Tunisia concentrates their digitization efforts on the development of digital distribution channels, namely remote banking deals as is Internet-banking solutions, mobile-banking or SMS banking yet. Indeed, the development of digital channels is now an essential step to reposition itself as a "digital bank" and ensure better customer relationship. For the Tunisian client begins to achieve some digital maturity and now shows seeker digital offerings, including for basic financial services consulting and downloading. So this approach is ideal for quickly meet customer needs and achieve quick-wins. However, 30\% of banks surveyed target deep processing projects, namely the digitalization process. Admittedly, this approach can be time consuming and costly, but it allows the bank to conduct a real digital revolution, which will easily adopt innovative technologies and to open up new opportunities for growth and new source income (Mui, 2019). 
A third strategy is feasible on the digital transformation: the launch of an independent brand and totally digital, like Webank of Attijari Bank. This approach was adopted by two of the banks surveyed.

All digital transformation projects must be carried by one or more branches within the bank in question, ensuring some support from top management and the sustainability of the project.

The digital transformation project is usually carried by two or more departments. The majority of the banks surveyed (70\%) involve senior management in their digital transformations. A sign that the topic of digitalization is taken seriously. Furthermore, the involvement of top management in the digital transformation and the fact that he has a solid knowledge of digital and its challenges, are key factors to the success of the project. The general direction is not the only one to carry the digital transformation project in Tunisian banks. Indeed, the project is led or co-led by the information system function at $50 \%$ of the banks surveyed. The IT functions are among the most qualified to carry the digital transformation (Husson, 2016).

They often have a budget that allows them to achieve digital projects, and rely on their legitimacy and expertise in technology. $40 \%$ of surveyed banks opt to create a new function dedicated to digital transformation. This choice is usually linked to an overall transformation strategy, with the establishment of a Chief Digital Officer (CDO) project on top of it. Only two banks on a set of 10 respondents said they do not rely on external service providers to assist them in the digital transformation. $80 \%$ of banks have recourse to other actors, namely FinTechs, software vendors, consulting firms or independent experts (Sharf, 2015). Indeed, the lack of competence in Tunisian banks, especially in terms of digital and new technologies is that they are obliged to call in experts or firms. Board who bring their expertise and accompany them during the project. Software companies have always been at the heart of transformation projects, both nationally and internationally. Such is the case of ATB example, that appealed in May 2019 to a digital solution developed by the Temenos banking software editor. As for FinTechs, they are often called as a service or solution providers, given their expertise in the field of digital. While the digital transformation is now a major concern for the majority of Tunisian banks and investments are dedicated to it. However, there are barriers that prevent banks from achieving their goals for digital.

$40 \%$ of banks surveyed find that Tunisian regulations in place represents a brake on innovation and digitalization (Mcwaters, 2015). Indeed, the laws relating to KYC prevent such digitize the account opening process from beginning to end, and a passage to the agency are required to verify the identity of the client. In addition, partnerships with FinTechs or technology start-ups in an objective to support the bank in its transformation through the provision of digital solutions have not been easy to conclude seen the rigid regulatory framework governing these entities, thus limiting their scope of operation. However, new regulatory measures adopted in Tunisia now facilitate the emergence and FinTech startups, BCT. Banks can thus capitalize on the expertise and the technological potential of these entities to facilitate their digital transformation.

Besides that regulatory barriers include the obsolescence of the information system, many banks are remedied through the acquisition of digital solutions to modernize or upgrade their core banking. Resistance to change and lack of a common strategic vision are also obstacles that $30 \%$ of surveyed banks confirm that they have encountered. Indeed, the establishment of a clear strategic plan for transformation, and the implementation of a digital culture among Tunisian banks are preliminaries any transformation project. Finally, 20\% of banks found that the main barrier to their digitalization is the lack of internal skills. Banks can remedy this through targeted recruitment. Besides the approach of transformation, a second axis heavily involved in defining the strategy of digitalization of the bank, namely the areas of investment, particularly in terms of distribution channels and new technologies.

\subsection{Investment Areas}

All digital transformation projects operate through investments that initially affect customer relations, through investments in distribution channels in order to adapt to customer needs. Second, a successful digital transformation must focus on new technologies, to enable the bank to ally with the new trends and open up new opportunities. Tunisian banks have now understood: in the era of digital, digital channels have priority, namely remote banking solutions: E-Banking and M-banking. First, they help streamline customer relationship by offering easy and instant access to service its bank via their mobile phone or computer. Then they can reduce costs by enabling the client to handle simple operations, freeing the advisor of low value-added tasks. Today, almost all Tunisian banks have already implemented remote banking solutions, and they still rely invest (70\% and $80 \%$ respectively of respondent banks are investing in Web-banking website and mobile app)

The Agency continues, in turn, in the heart of the bank's investments. Indeed, it is Tunisia's first point of contact between bank and client. Thus, investments are dedicated each year for many reasons (network expansion, changes 
in format ...). As for the contact center, $30 \%$ of banks surveyed plan to invest there. Similar to the automatic cash machine, with investments that aim to cover more functionality (currency exchange, mobile phone recharge, payment of cash ...). Investments affecting digital channels, including e-banking solutions and M-banking, often designed to improve ergonomics. However, their main objective is to be added features not covered previously, or improve existing, to offer customers a better user experience and allow to carry a maximum of transactions on your mobile or computer.

The majority of Tunisian banks are designed by their investments to enhance the functionality of transfers and direct debit. This shows that the banks have well spotted the benefit to be gained if it delegates this type of transaction to the customer. Similarly for consultation and downloading, basic services that any remote banking offer must have, however, it is necessary to ensure that these features are covered optimally.

Among the most popular features found ways to interact with the bank, with $40 \%$ of the banks surveyed that rely invest. Indeed, the customer relationship is now one of the key areas of the bank, and ensures good interaction with his client can only fuel and enrich the relationship. The chatbot is a great way to achieve this. Based on Artificial Intelligence and Machine Learning, they provide instant interaction with the customer, answering all his questions. The videoconferences are in turn a good way to put the customer, in touch with the advisor or an expert, without having to travel to the agency account opening services and credit demand are almost nonexistent at the Digital offers Tunisian banks. Yet only 20 to $30 \%$ of the banks surveyed plan to invest there. The figure below shows the lack of these features, and gives us an insight on the various banking products remotely Tunisian banks (not exhaustive):

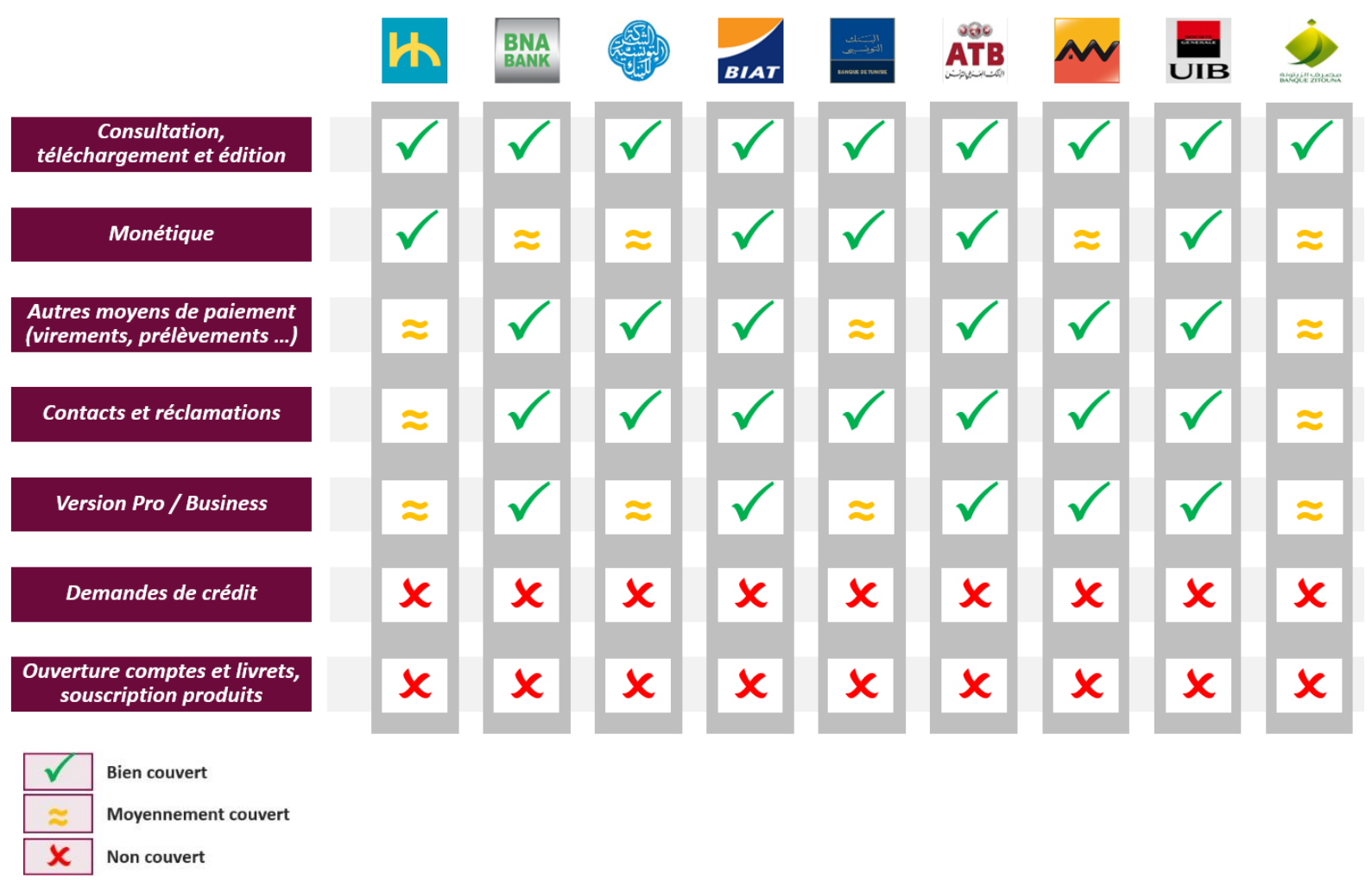

Source: Matine Consulting, 2018.

Moreover, budget management tools and the stock market spaces where the customer view their portfolio and managing its orders are not yet developed to the level of the offers E-banking and M-banking Tunisian banks. 
However, these features are available in most of the solutions developed by French banks. Beyond the remote banking offer, the second investment priority Tunisian banks in terms of distribution channels is the agency network.

Unlike European trends, Tunisian banks have no plans to reduce the number of branches. Rather, they are rather a view of the expansion, the key word being nearby. Indeed, half of the banks surveyed are planning a moderate expansion of its branch network (growth $<5 \%$ per year), and 20\% expect a strong expansion (growth $>5 \%$ per year). On the other side, $30 \%$ of banks are intact maintain the size of their networks. None of the banks showed the intention to close some outlets. The figure below presents the evolution of the branch network of Tunisian banks:

Tunisian banks have encouraged the rapid expansion of their network for the period from 2013 to 2015. Then the banks have maintained their expansion strategy, but evolution has turned into a statement in the opening points sales. The banks' strategies are different in this aspect. The first 10 local banks have reduced the pace of opening new branches as new market players are now expanding their network. This wave of network expansion was accompanied with some banks by investments on the agency's size. Most vis-à-vis the evolution of efforts the agency format focused on the development of self-service areas. Indeed, many Tunisian banks now have self-service areas, where the customer can directly support some simple operations, namely the withdrawal and payment of cash, delivering checks, the exchange ... Some banks Tunisian offer 24/7 access to their self-service areas with possible access via credit card. $30 \%$ of banks surveyed have no agency for processing projects. They are limited for the moment to promote their proximity expanding their network of outlets. In contrast, only $10 \%$ of banks have to change the format of their agency to new models: Small and medium sized agencies, which are often only agents for the treatment of ongoing operations or agencies specialized by customer segment. Large windows agencies or agencies (flagship) which are modern agencies presenting all offers and products of the bank, like the flagship store of Zitouna. Finally the digital agencies, equipped with WiFi, touch screens and tablets, where customers can ask at a computer, alone or accompanied by his adviser.

A second component, as important as the development of distribution channels, captures the attention of the majority of banks, both domestic and international, namely the adoption of new technologies. In this context, many banks have invested heavily to take advantage of great benefits that these technologies offer 8 of 10 banks plan to invest in the Data (Data analytics/Big data). This shows that the majority of banks are now aware of the specific issues, particularly in terms of customer relations. A good mastery of data and technology tools that come with it allows the bank to customize the offer, according to the specifications of each client, and so loyalty. Moreover, the adoption of the data technologies to optimize marketing campaigns and improve risk management of the bank, including fraud detection.

Regarding the APIs, 50\% of the bank showed themselves enthusiastic about investing. Indeed, implementing APIs allows the bank to move towards Open Banking, and thus open up new opportunities for growth and revenue. Something that many Tunisian banks realized.

NFC technology is also beginning to spread in Tunisia. This technology is used for contactless payment via credit card. Some Tunisian banks have already developed this kind of solution, including BIAT, Amen Bank, UBCI and Zitouna. These cards using NFC technology, it is enough to bring the TPE to complete the transaction. As for Blockchain, artificial intelligence and cloud, Tunisian banks have not paid enough attention to these technologies, or they assume that it is still premature to talk about. However, exceptions exist. For example, a Blockchain solution, called I-Trade is being deployed within Wifak Bank. Investments in new technologies must be accompanied by an appropriate marketing and communication policy, which aims firstly to promote products and services of the bank, on the other hand to ensure interaction with the customer and provide quality content. To do this, a digital marketing strategy must be put in place with $62 \%$ penetration in Tunisia according to the report of We Are Social, social networks are unanimous from banks. In effect, aware of the challenge that this channel represents all Tunisian banks will invest it, in an effort to reach as many people, but also to animate communities and be present to its customers. Moreover, the job of Community Manager is now essential to any organization.

Search Engine Marketing (SEM), or the marketing on search engines is also a very viable option for our banks, especially as Google is the 3rd most visited site in Tunisia from We Are Social (after Facebook and YouTube). Thus, the ranking on search engines allows the bank to improve its position in the results provided in response to a keyword search. For example, a bank emits X type AdWords ads on Google on the keyword "consumer credit". Any research, including "consumer credit" will bring up the offer of the bank first (or top). Thus, it is gaining visibility it can convert into sales. 
YouTube is the 2nd most visited website in Tunisia, represents a huge opportunity that many Tunisian banks have not yet entered. Publish educational quality content, or advise customers on available offers via innovative and original videos, reflect the expertise of the bank and can increase its notoriety.

Advertising in information sites and electronic journals are the most basic. They generally consist of banners containing a special offer from the bank, which aims to capture the user's attention and direct it to the site. However, these ads are most effective if they are targeted (e.g. broadcast advertising of a product of "study credit" on the websites of universities).

Beyond investments, banks are now using external players to carry their digital transformation, namely FinTechs.

\subsection{Relationship With FinTechs}

The relationship between banks and FinTech can be a competitive relationship, certainly, especially for FinTechs operating in the same field of activity the bank, namely the neo banks, payment institutions, platforms crowdfunding etc. However, throughout the world, the banks now more partnerships and investments in FinTechs in order to benefit from quick access to technological expertise and capacity for innovation. What about the case of Tunisian banks?

In Tunisia, there is a varied range of FinTechs operating in various sectors. The table below gives us an overview. However, beyond the Tunisian FinTechs, our banks may use the services and solutions of any other FinTech, regardless of nationality.

Table 4. List of Tunisian FinTechs (Not exhaustive)

\begin{tabular}{|c|c|c|c|}
\hline FinTech & Field of Activity & year of creation & Physical location \\
\hline Bitaka Cards \& Solutions & Payments/Transactions & 2003 & Tunisia \\
\hline TOOLS4COM & B2B Offers - Billing & 2008 & Tunisia \\
\hline Viamobile & Payments/Transactions & 2009 & Tunisia \\
\hline Afrikwity & Crowdfunding - investment & 2013 & France \\
\hline Cofundy & Crowdfunding - donations & 2013 & France \\
\hline Sobflous & Payments/Transactions & 2013 & Tunisia \\
\hline Hadrum & B2B Offers & 2013 & Tunisia \\
\hline Expensya & B2B Offers - Billing & 2014 & France \\
\hline \multirow{2}{*}{ Paypos } & Payments/Payment terminals/Services & & \\
\hline & banks & 2014 & Tunisia \\
\hline Link \& Pay & Payments/Transactions & 2015 & France \\
\hline \multirow{2}{*}{ ilBoursa } & Support to the investment decision/analysis & & \\
\hline & financial & 2016 & Tunisia \\
\hline Swiver & B2B Offers & 2016 & Tunisia \\
\hline Digitus & Cryptomonnaie/Blockchain & 2016 & Tunisia \\
\hline Facturation.tn & B2B Offers - Billing & 2017 & Tunisia \\
\hline Flouci & Payments/Transactions & 2017 & Tunisia \\
\hline DigiCash & Payments/Transactions & 2017 & Tunisia \\
\hline Paymee & Payments/Transactions & 2018 & Tunisia \\
\hline
\end{tabular}

Source: Matine Consulting, 2018.

The form of the most common cooperation with the Tunisian banks is the use FinTechs as:

Solution Providers: For example, a bank integrates mobile payment solution developed by FinTech in its remote banking offer, like BIAT which adopted the M-Dinar solution, or with Attijari MobiCash. 
Providers: the example of the FinTech Keyrus that accompanied the Banque de l'Habitat (BH) in the establishment of a decision-computer system and a data warehouse.

The same FinTech is also accompanied by BIAT in the definition of an industrialization process of the production cycle of its dashboards. Moreover, Attijari Bank in turn appealed to Attila FinTech specializes in digital marketing for the promotion of its online banking solution Webank.

Another collaborative approach also begins to spread to the Tunisian banks, namely the incubation and events aimed at FinTechs and start-ups in general (hackathons, conference ...). These methods are very fruitful for both parties. On one hand, the FinTech accompanied from the design stage and find the support and resources necessary for its development. On the other hand, the bank enjoys exclusive access to the expertise and the particular technological potential of the FinTech.

However, the equity investment and acquisitions FinTech by banks is an approach that is not yet developed in Tunisia. This can be explained by structural and cultural differences of the two parties, or the lack of a unified vision for collaboration. Unlike investment flows of Western banks, where the latter are racing to acquire the best FinTechs space. Just like the US bank Goldman Sachs, which alone has invested in over 45 FinTechs different areas according to the CB Insights report published in 2018.

Finally, the majority of Tunisian banks have collaborated or collaborate with FinTechs, and through different approaches. So the question is this: What FinTechs our banks are more likely to partner with?

As part of their collaboration strategy, 50\% of banks surveyed have opted for specialized FinTechs payment and fund transfer. Indeed, the new law of payment institutions has given rise to many actors in this sector. The banks therefore form partnerships with these FinTechs to integrate their payment solutions, especially as most of these entities are developed by the telephone operators they enjoy broad customer bases (Ooredoo Tunisia: MobiFlouss, MobiCash/Tunisie Telecom: M-Dinar, MobiDinar, Mobilplay/Orange MobiMoney).

Risk management is the second choice of Tunisian banks in working with FinTechs. This is explained by the significant technological potential of documents available, which allows them to establish risk management systems based on the mastery of the data, with Big Data technologies and artificial intelligence.

However, Tunisian banks have not paid enough interest FinTechs specialized in customer relationship and RegTechs. Indeed, specialized in customer relationship FinTechs allow banks via their solutions, although segmenting the offer as required and customer characteristics, and ensure a better relationship with them. As for RegTechs they give banks the opportunity to automate many compliance processes, and thus gain in cost and time.

It is true that cooperation between Tunisian banks and FinTechs can only be fruitful for both parties and enriches the digital offer addressed to the customer. However, some of FinTechs disruptive nature tends to compete with banks in their areas of activity. In Europe, the market share held by FinTechs greatly increase at the expense of those banks. So in the case of Tunisia, what is the main threat from these entities and which competes our banks $80 \%$ of banks surveyed are aware of the competitive threat from FinTechs. Indeed, the two main factors of this threat is the customer experience and innovation. However, Tunisian banks do not give enough importance to the service cost aspect, then that is one of the major catalysts for the emergence of FinTechs worldwide. In Tunisia, the price index of banking services (IPSB) increased by $65.8 \%$ since 2010, according ilBoursa. Added to this the statistics of the OTIC (Tunisian Organization Informing Consumer) published in February 2018 and which reported that 84\% of Tunisians are dissatisfied banking. These two factors together mean that the threat of FinTechs is real, especially in terms of costs. Because these entities are based often on transparent tariff structures and offer their products and services to consumers at low cost.

\section{Conclusion}

The wave of digital transformation that has affected the whole world has not spared Tunisia. Indeed, the majority of Tunisian banks were then launched in digitalization projects with a goal to best meet customer needs, to become more agile and reduce operating costs. To do so, the Tunisian banks initially focused their efforts for the development of their digital offerings. Today, almost all banks have a remote banking offer that includes an Internet solution Banking and Mobile Banking solution. Some of these banks have even been awarded prizes for their digitization initiatives, the image of the STB which was voted Best Digital Bank in North Africa by the Arab Union of Banks. Or Amen Bank, which has been designated by the Trusted Advisors firm as the best bank in North Africa for the Digital Transformation. However, few banks have initiated discussions on a deep digitalization affecting banking processes from end to end. 
These digital transformation projects have been accompanied by significant investments in the first place to improve the digital distribution channels, particularly in terms of functionality covered in order to offer the customer a better experience from their PC or mobile. Second, the investments affected the agency network. In Tunisia, contrary to the European trend, the majority of banks are always in the context of expanding their network of outlets. Develop self-service areas is the second priority of our banks' branch network.

Finally, many of the investments are dedicated to the adoption of new technologies, including Big Data and Data Analytics. Which indicates that our banks are aware of the challenge that these innovation areas represent.

In relation to their environment, many Tunisian banks have collaborated with FinTechs, especially those specializing in payment or risk management. However, much remains to grasp opportunity, namely cooperation with RegTech that can free our banks heavy loads imposed by the regulations.

\section{References}

Floer, J. (2018). Fintech. Retrieved 1st February, 2019, from On Richesse-et-finance.com

Fox, S., \& Greenspan, M. (2019). What is FinTech? Retrieved February 13, 2017, from EToro.com

Husson, L.-E. (2016). These Fintech that disrupt banking and insurance. Challenges, 2, 2016.

Lieber, R. (2014).Financial Advice for People Who Are not Rich. The New York Times, 4, 2014.

McWaters, J. R. (2015). The Future of Financial Services: How Disruptive innovations are reshaping the way financial services are structured, provisioned and Consumed. World Economic Forum, 2015, 125

Mui, R. (2019), Singapore FinTech investments more than doubles to US \$365m in 2018 amid global surge Accenture. The Business Times, 2.

Sharf, S. (2015). The Forbes Fintech50. Forbes, 12, 2015.

Schueffel, P. (2017). Taming the Beast: A Scientific Definition of Fintech. Journal of Innovation Management, 4(4), $32-54$.

Scholten, U. (2019). Banking-as-a-Service - what you need to know. Venture Skies.

Vauplane, Pierre-Alexis. (2015). Fintech 2020. Growth More and SME Finance.

Vauplane, Pierre-Alexis. (2015). FinTech 2020: Resume initiative. Les Echos.

World Development Report. (2016). Digital Dividends. Retrieved from https://www.worldbank.org/en/ publication/wdr2016 